ISSN 2075-4701

www.mdpi.com/journal/metals/

Article

\title{
Separation and Recycling for Rare Earth Elements by Homogeneous Liquid-Liquid Extraction (HoLLE) Using a pH-Responsive Fluorine-Based Surfactant
}

\section{Shotaro Saito ${ }^{1}$, Osamu Ohno ${ }^{1}$, Shukuro Igarashi ${ }^{1, *}$, Takeshi Kato ${ }^{2}$ and Hitoshi Yamaguchi $^{3}$}

1 Department of Biomolecular Functional Engineering, College of Engineering, Ibaraki University, 4-12-1 Nakanarusawa-cho, Hitachi, Ibaraki 316-8511, Japan;

E-Mails: 14nd103r@vc.ibaraki.ac.jp (S.S.); osamu.ohno.31@vc.ibaraki.ac.jp (O.O.)

2 Industrial Technology Institute of Ibaraki Prefecture, 3781-1 Nagaoka, Ibaraki-machi, Ibaraki-gun, Ibaraki 311-3195, Japan; E-Mail: katou@kougise.pref.ibaraki.jp

3 Research Center for Strategic Materials, National Institute for Material Science, 1-2-1 Sengen, Tsukuba, Ibaraki 305-0047, Japan; E-Mail: yamaguchi.hitoshi@nims.go.jp

* Author to whom correspondence should be addressed; E-Mail: shukuro.igarashi.3@vc.ibaraki.ac.jp; Tel.: +81-294-38-5059; Fax: +81-294-38-5078.

Academic Editor: Suresh Bhargava

Received: 27 July 2015 / Accepted: 25 August 2015 / Published: 27 August 2015

\begin{abstract}
A selective separation and recycling system for metal ions was developed by homogeneous liquid-liquid extraction (HoLLE) using a fluorosurfactant. Sixty-two different elemental ions (e.g., Ag, Al, As, Au, B, Ba, Be, Bi, Ca, Cd, Ce, Co, Cr, Cu, Dy, Er, Eu, Fe, $\mathrm{Ga}, \mathrm{Gd}, \mathrm{Ge}, \mathrm{Hf}, \mathrm{Hg}$, Ho, In, Ir, La, Lu, Mg, Mn, Mo, Nb, Nd, Ni, Os, P, Pb, Pd, Pr, Pt, Re, $\mathrm{Rh}, \mathrm{Ru}, \mathrm{Sb}, \mathrm{Sc}, \mathrm{Se}, \mathrm{Si}, \mathrm{Sm}, \mathrm{Sn}, \mathrm{Sr}, \mathrm{Ta}, \mathrm{Tb}, \mathrm{Te}, \mathrm{Ti}, \mathrm{Tl}, \mathrm{Tm}, \mathrm{V}, \mathrm{W}, \mathrm{Y}, \mathrm{Yb}, \mathrm{Zn}$, and Zr) were examined. By changing $\mathrm{pH}$ from a neutral or alkaline solution $(\mathrm{pH} \geq 6.5)$ to that of an acidic solution ( $\mathrm{pH}<4.0$ ), gallium, zirconium, palladium, silver, platinum, and rare earth elements were extracted at $>90 \%$ efficiency into a sedimented Zonyl FSA ${ }^{\circledR}$ $\left(\mathrm{CF}_{3}\left(\mathrm{CF}_{2}\right)_{n}\left(\mathrm{CH}_{2}\right)_{2} \mathrm{~S}\left(\mathrm{CH}_{2}\right)_{2} \mathrm{COOH}, n=6-8\right)$ liquid phase. Moreover, all rare earth elements were obtained with superior extraction and stripping percentages. In the recycling of rare earth elements, the sedimented phase was maintained using a filter along with a mixed solution of THF and $1 \mathrm{M}$ sodium hydroxide aqueous solution. The Zonyl FSA ${ }^{\circledR}$ was filtrated and the rare earth elements were recovered on the filter as a hydroxide. Furthermore, the filtrated Zonyl FSA was reusable by conditioning the subject $\mathrm{pH}$.
\end{abstract}


Keywords: homogeneous liquid-liquid extraction; HoLLE; phase separation phenomenon; fluorosurfactant; ion association; rare earth elements; separation and recycling; hydrometallurgy

\section{Introduction}

Many kinds of rare earth elements such as neodymium, europium, and gadolinium have been recently used in the development of new materials. However, the production of scandium, yttrium, and lanthanoids, collectively referred to as rare earth elements, is not yet widespread across the world. Hence, the potential production of these materials via waste recycling processes has become increasingly important; however, the costs and efficiencies of these recycling processes pose inherent problems. The mutual metal separation method is generally classified into wet and dry methods. Here, the wet method has been employed for reasons such as separation accuracy and energy savings. This typical method utilizes a solvent extraction process which uses solvents that are immiscible with each other. In addition to this process, various separating agents and methods for metal separation have also been recently developed. These include solvent extraction using ionic liquids [1,2], phase separation extraction using stimuli-responsive polymers [3-6], and solid-phase extraction using the adsorption effect of biological materials [7-9]. Among these, it is especially noteworthy that in 1988, Igarashi and Yotsuyanagi discovered the $\mathrm{pH}$-dependent phase separation phenomenon, resulting from the addition of acid to a perfluorooctanoic acid (PFOA) aqueous solution containing trace amounts of acetone [10]. An oily, small secondary phase is resultantly produced, with the target substance ultimately being extracted from therein. Furthermore, the formation of a stable liquid phase which consists of $\mathrm{PFOA}^{-}$and quaternary salt $\left(\mathrm{Q}^{+}\right.$such as tetrabutylammonium ion $\left(\mathrm{TBA}^{+}\right)$) was subsequently reported in the following year (1989) [11,12]. The produced liquid phase is stable in water and air; hence, it is known to be the same type as the early ionic liquid reported in 1992 [13] because the liquid is produced at room temperature by ionic associations of the subject cationic and anionic organic compounds (e.g., melting point; $-2.3{ }^{\circ} \mathrm{C}$ in $\mathrm{PFOA}^{-} / \mathrm{TBA}^{+}[14]$ ). This formation reaction of an ionic liquid is applied at the same time as the homogeneous liquid-liquid extraction method (HoLLE, type I in Figure 1). Many research papers have been published from the viewpoint of microextraction methods for trace components [15-20]. Hence, HoLLE, a separation method that uses these characteristics effectively, was conceived. In HoLLE, because an aqueous phase and an organic phase are in a homogeneous state at the starting point of extraction, a mechanically vigorous agitation for increasing the contact interface between the aqueous and organic phases in the solvent extraction process is not necessary. This separation method is the extraction to the water-immiscible sedimented phase for the target substance by providing stimuli such as changes in $\mathrm{pH}$, temperature, and light. Some separation and concentration methods for metal chelates using surfactants such as PFOA and slight amounts of water-miscible organic solvents (such as acetone, tetrahydrofuran, etc.) have been reported [15-17,19]. In addition, a concentration method for rare earth elements using phosphoric acid and di(2-ethylhexyl)ester (D2EHPA) as an extracting agent in $\mathrm{PFOA}^{-} / \mathrm{TBA}^{+}$has also been reported [21]. 


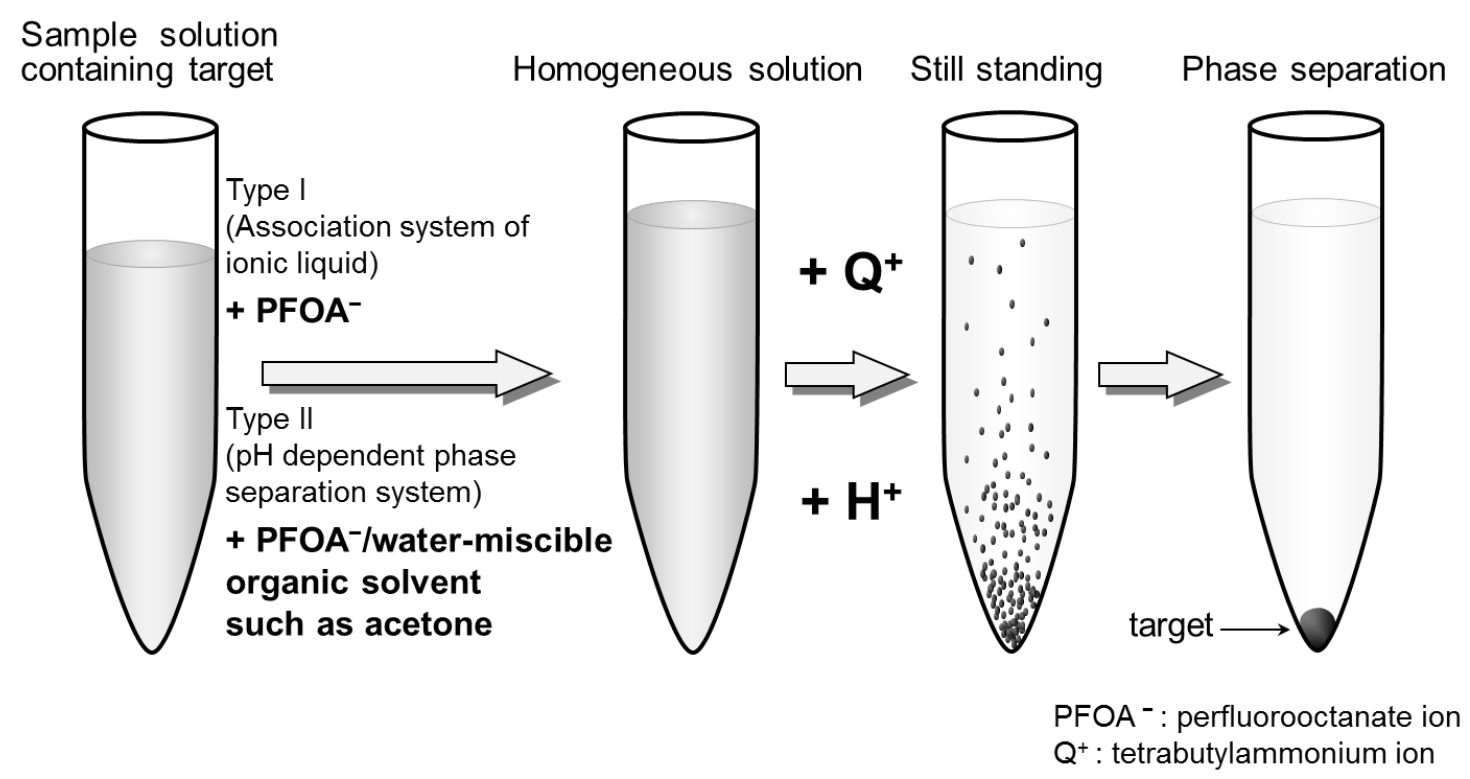

Figure 1. Scheme of homogeneous liquid-liquid extraction method (HoLLE).

In this study, Zonyl FSA ${ }^{\circledR}$, which is an alternative substance of $\mathrm{PFOA}^{-}$, was used as a phase separation agent in HoLLE. Zonyl $\mathrm{FSA}^{\circledR}$ is a 3-[2-(perfluoroalkyl)ethylthio]propanoic acid $\left(\mathrm{CF}_{3}\left(\mathrm{CF}_{2}\right)_{n}\left(\mathrm{CH}_{2}\right)_{2} \mathrm{~S}\left(\mathrm{CH}_{2}\right)_{2} \mathrm{COOH}, n=6-8\right)$, with an acid dissociation constant ( $\left.\mathrm{p} K_{\mathrm{a}}\right)$ of approximately 6 [22]. Therefore, this compound displays weak acidity because a spacer of some methylene groups is introduced between the fluorocarbon chain and the hydrophilic group, as compared to the strongly acidic PFOA. Applications of the separation and concentration of chlorophyll-a [22], silver complex [23], copper complex [24], indium complexes [25], and aluminum/titanium with 1,10-phenanthroline complexes [26] have been reported by HoLLE using this phase-separating agent.

In this paper, the extraction for 62 kinds of elements were examined and a high-efficiency separation and recycling system of rare earth elements using Zonyl FSA ${ }^{\circledR}$ as a phase-separating agent based on HoLLE, without the use of a chelating reagent, is described.

\section{Experimental Section}

\subsection{Reagents}

Zonyl FSA ${ }^{\circledR}$ was purchased from DuPont (Wilmington, DE, USA). Sixty-two types of elemental ions (Ag, Al, As, Au, B, Ba, Be, Bi, Ca, Cd, Ce, Co, Cr, Cu, Dy, Er, Eu, Fe, Ga, Gd, Ge, Hf, Hg, Ho, In, Ir, $\mathrm{La}, \mathrm{Lu}, \mathrm{Mg}, \mathrm{Mn}, \mathrm{Mo}, \mathrm{Nb}, \mathrm{Nd}, \mathrm{Ni}$, Os, P, Pb, Pd, Pr, Pt, Re, Rh, Ru, Sb, Sc, Se, Si, Sm, Sn, Sr, Ta, Tb, $\mathrm{Te}, \mathrm{Ti}, \mathrm{Tl}, \mathrm{Tm}, \mathrm{V}, \mathrm{W}, \mathrm{Y}, \mathrm{Yb}, \mathrm{Zn}$, and $\mathrm{Zr}$ ) were selected and their predetermined concentrations were prepared by diluting 1000-ppm standard solutions (received from Kanto Chemicals, Tokyo, Japan) with distilled water. Concretely, $\mathrm{Ag}(\mathrm{I}), \mathrm{Al}(\mathrm{III}), \mathrm{Ba}(\mathrm{II}), \mathrm{Be}(\mathrm{II}), \mathrm{Bi}(\mathrm{III}), \mathrm{Ca}(\mathrm{II}), \mathrm{Cd}(\mathrm{II}), \mathrm{Ce}(\mathrm{III}), \mathrm{Co}(\mathrm{II}), \mathrm{Cr}(\mathrm{VI})$, $\mathrm{Cu}(\mathrm{II}), \mathrm{Dy}(\mathrm{III}), \mathrm{Er}(\mathrm{III}), \mathrm{Eu}(\mathrm{III}), \mathrm{Fe}(\mathrm{II}), \mathrm{Ga}(\mathrm{III}), \mathrm{Gd}(\mathrm{III}), \mathrm{Hg}(\mathrm{II}), \mathrm{Ho}(\mathrm{III}), \mathrm{In}(\mathrm{III}), \mathrm{La}(\mathrm{III}), \mathrm{Lu}(\mathrm{III}), \mathrm{Mg}(\mathrm{II})$, Mn(II), Nd(III), Ni(II), Pb(II), Pd(II), Pr(III), Sc(III), Se(IV), Sm(III), Sr(II), Tb(III), Tl(I), Tm(III), $\mathrm{V}(\mathrm{V}), \mathrm{Y}(\mathrm{III}), \mathrm{Yb}(\mathrm{III}), \mathrm{Zn}(\mathrm{II})$, and $\mathrm{Zr}(\mathrm{IV})$ were $0.01-1 \mathrm{M}$ of nitric acid aqueous solution. As(III), Au(III), Ir(IV), Mo(VI), Os(IV), Pt(II), Rh(III), Ru(III), Sb(III), Sn(II), and Te(IV) were 0.4-6 M of hydrochloric acid aqueous solution. $\mathrm{Hf}(\mathrm{IV}), \mathrm{Nb}(\mathrm{V})$, and $\mathrm{Ta}(\mathrm{V})$ were 1-3 $\mathrm{M}$ of hydrofluoric acid aqueous solution. 
$\mathrm{Ge}(\mathrm{IV})$ and $\mathrm{Si}(\mathrm{IV})$ were $0.2-0.4 \mathrm{M}$ potassium hydroxide solution. Ti(IV) was $2 \mathrm{M}$ sulfuric acid aqueous solution. Each of $\mathrm{B}(\mathrm{III}), \mathrm{P}(\mathrm{V}), \mathrm{Re}(\mathrm{VII})$, and $\mathrm{W}(\mathrm{VI})$ were aqueous solution of oxo acid salts containing some ammonium ion. All element solutions were diluted with distilled water to 100 fold. Tetrahydrofuran (THF), acetic acid, sodium acetate, sodium hydroxide, acetone, and all other reagents used were of commercially available analytical grade unless otherwise specified. The utilized filter (for all cases) was a Merck Millipore hydrophilic PTFE filter JAWP02500 (Omnipore, pore size: $1.0 \mu \mathrm{m}$, Billerica, MA, USA).

\subsection{Apparatuses}

The following apparatuses were used: $\mathrm{pH}$ meter $=$ Model F-51, manufactured by Horiba Ltd. (Kyoto, Japan); centrifugal separator = Model LC-100, manufactured by TOMY SEIKO Co., Ltd. (Tokyo, Japan); vacuum pump = Model MDA-015, manufactured by ULVAC (Kanagawa, Japan); ICP optical emission spectrometer = Model iCAP6300, manufactured by Thermo Fisher Scientific (Waltham, MA, USA).

\subsection{Experimental Procedure}

\subsubsection{Extraction Characteristics of Elements by HoLLE with Zonyl FSA ${ }^{\circledR}$}

The following were added into a glass vial: $0.5 \mathrm{~mL}$ of elemental mixed solution (each element concentration: $10 \mathrm{ppm}), 1.0 \mathrm{~mL}$ of THF, and $1.0 \mathrm{~mL}$ of Zonyl FSA ${ }^{\circledR}$. Next, $7.5 \mathrm{~mL}$ of acetic acid/sodium acetate buffer solution $(\mathrm{pH}=4)$ were added to bring the total mixture volume up to $10 \mathrm{~mL}$. The mixture was then centrifuged for $10 \mathrm{~min}$ at $2000 \mathrm{rpm}$ to separate the sedimented (Zonyl FSA ${ }^{\circledR}$ ) phase and the supernatant (aqueous) phase. Each rendered post-centrifugal phase volume was $V_{\text {aq. }}=9.95 \mathrm{~mL}$ and $V_{\text {Zonyl FSA }^{\circledast}}=50 \mu \mathrm{L}$. The concentration of elemental ions in the aqueous phase was determined by ICP-OES.

The extraction percentage $(E \%)$ of elemental ions was calculated as

$$
E \%=100\left(1-C_{\text {aq. }} / C_{\text {Total }}\right)
$$

where $C_{\text {Total }}$ and $C_{\text {aq. }}$. represent the total concentration of the added element and the concentration of the element in the aqueous phase after separation, respectively. Of note, the error range of each element's extraction percentage is $\pm 5 \%$ or less.

2.3.2. The Recovery of Elements from the Zonyl FSA ${ }^{\circledR}$ Phase and the Redissolution of the Zonyl FSA ${ }^{\circledR}$ Phase

A water-immiscible Zonyl FSA ${ }^{\circledR}$ phase has retained the state of a stable liquid phase in the aqueous solution, and the elemental ions were recovered by filtration. In the recovery of targets, rare earth elements (Sc, Y, and lanthanoids) were well extracted by the experiment described in Section 2.3.1, and they were thus selected as targets. A Zonyl FSA ${ }^{\circledR}$ phase (approximately $50 \mu \mathrm{L}$ ) was produced after rare earth elemental extraction, which held on the hydrophilic PTFE filter. Water-immiscible Zonyl FSA ${ }^{\circledR}$ was filtered by adding $1 \mathrm{~mL}$ of sodium hydroxide and THF solution, which were mixed at a volume ratio of $1: 1$. The elements were trapped on the filter as hydroxides, the recovery percentage of elemental ions 
in the filtrate phase was determined by ICP-OES. Furthermore, the rare earth elements were recycled again by the same procedure outlined in Section 2.3.1 using the filtrated Zonyl FSA ${ }^{\circledR}$.

\section{Results and Discussion}

\subsection{The Extraction of THF within the Phase Separation Phenomenon}

As solubilizing agents for Zonyl FSA ${ }^{\circledR}$, acetone and THF are examined. THF was selected from the viewpoint of its concentration time and operability, because it was already reported that the sedimented volume and its associated viscosity increase in the case of using acetone [22]. The relationship of the volume percentage of THF in the sedimented volume showed linear behavior in the range of 10-35 vol. \% for the THF volumes shown in Figure 2 below. In the case of below 10 vol. \% THF, the Zonyl FSA ${ }^{\circledR}$ phase precipitated fine solid particles. Moreover, Zonyl FSA ${ }^{\circledR}$ did not form a sedimented phase in the case of THF exceeding $50 \mathrm{vol}$. \%. Therefore, THF volume in this system was ultimately deemed appropriate for $10 \mathrm{vol} . \%$.

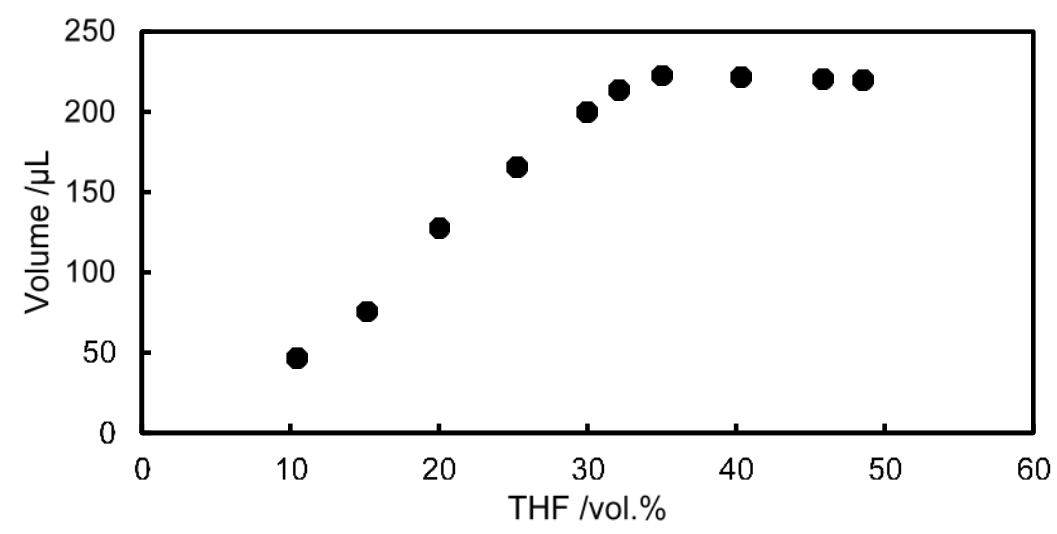

Figure 2. Relationship between the volume percentage of THF and the volume of sedimented phase. $\left(\right.$ Zonyl FSA $\left.{ }^{\circledR}\right)=10$ vol. \%; pH $=4$.

\subsection{Screening of Elements}

The experimental procedure was performed according to Section 2.3.1. The percentage of extracted element ions in the sedimented phase is shown in Figure 3. Here, some element ions in the sample solution are estimated to exist as different type species such as a free metal ion, an anion complex such as gold chloride complex or platinum chloride complex, and an oxo anion species such as boric acid or phosphoric acid. Gallium, zirconium, palladium, silver, platinum, and rare earth elements (except for praseodymium) were obtained with a high extraction percentage; however, gold, indium, and germanium were obtained with a very low extraction percentage. With respect to rare earth elements, most rare earth elements are stable in the trivalent state, and they do not produce a hydroxide unless the $\mathrm{pH}$ range is of weak basicity to neutrality, e.g., since the solubility product constant $\left(K_{\mathrm{sp}}\right)$ of lanthanum is $1.0 \times 10^{-19}$ [27], it does not precipitate as a hydroxide during the extraction procedure $(\mathrm{pH}=4.0)$. On the other hand, only cerium was obtained with a notably low extraction percentage. This is because cerium is thought to exist in trivalent and tetravalent states in an aqueous solution with a $\mathrm{pH}$ of approximately 4 . Based on this reason, tetravalent cerium is precipitated as a hydroxide in an acidic condition and, thus, is still 
susceptible to hydrolysis $[28,29]$. Therefore, the extraction into the sedimented Zonyl FSA ${ }^{\circledR}$ phase can present inherent challenges because of the fact that tetravalent cerium has usually already hydrolyzed at the time of extraction in a $\mathrm{pH}$ equal to 4.
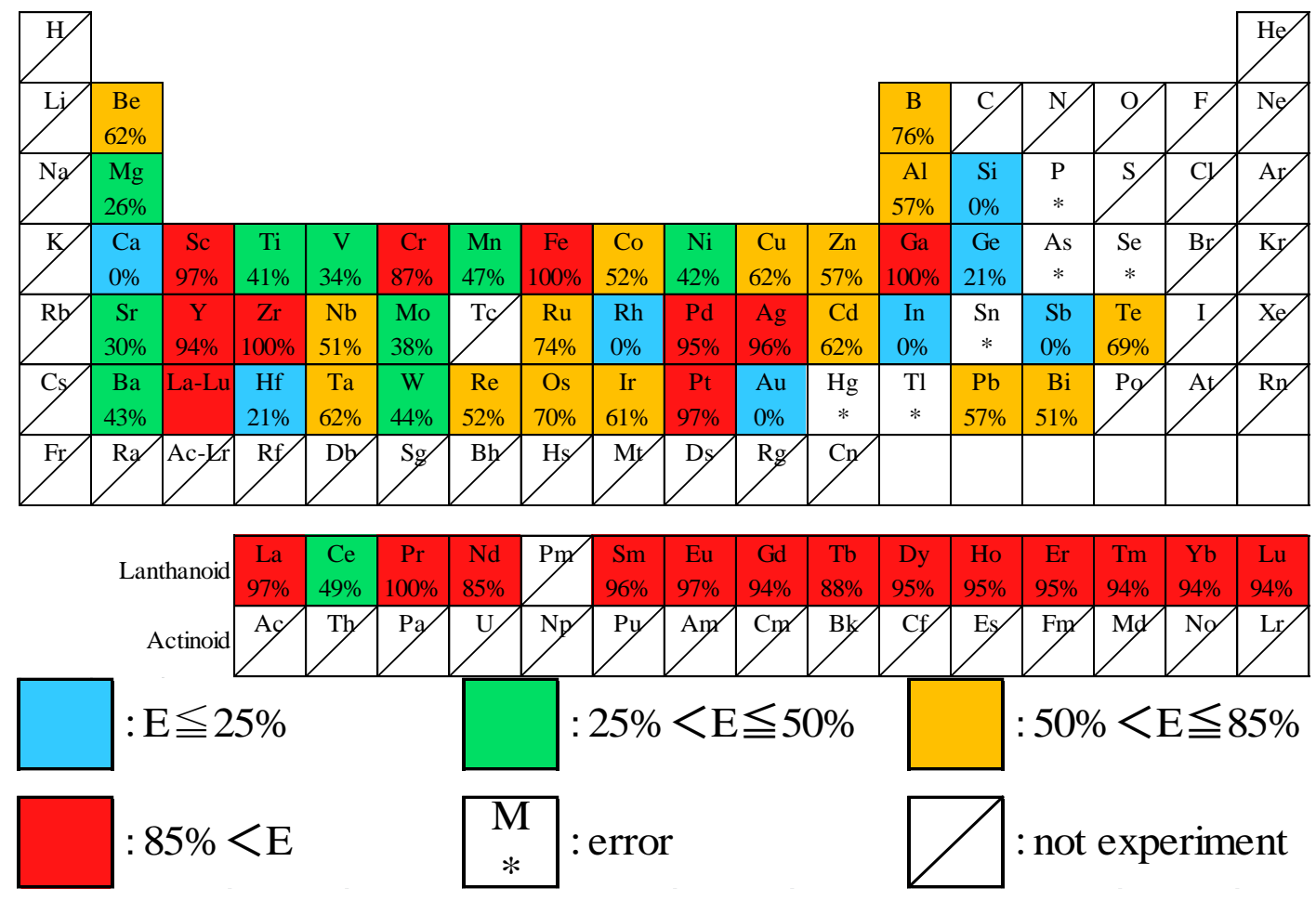

Figure 3. Summary of the extraction percentages for elemental ions with Zonyl FSA ${ }^{\circledR}$.

\subsection{Stripping of Rare Earth Elements}

The extraction behavior of elements into the Zonyl FSA ${ }^{\circledR}$ liquid phase was examined by focusing on rare earth elements. Filtration operation by the filter was evaluated for the sedimented phase containing rare earth elements. The sedimented phase was held/maintained by a microsyringe on a Teflon filter (Pore size: $1 \mu \mathrm{m}$ ). The rare earth elements were collected on the filters as hydroxides by a 1:1 mixed solvent of $1 \mathrm{~mL}$ THF and $1 \mathrm{M}$ sodium hydroxide aqueous solution, whereas the Zonyl FSA ${ }^{\circledR}$ was dissolved in the procedure. That rare earth elements had been stripped was confirmed by measuring Zonyl FSA ${ }^{\circledR}$ aqueous solution that was dissolved and filtrated using ICP-OES (Table 1).

Table 1. Stripping percentages of rare earth elements from the Zonyl FSA ${ }^{\circledR}$ phase.

\begin{tabular}{ccccccccccccccccc}
\hline Metal & Sc & Y & La & Ce & Pr & Nd & Sm & Eu & Gd & Tb & Dy & Ho & Er & Tm & Yb & Lu \\
\hline Recovery \% & 81 & 92 & 88 & 90 & 91 & 88 & 91 & 92 & 92 & 91 & 92 & 92 & 84 & 92 & 92 & 92 \\
\hline
\end{tabular}

\subsection{Reuse of Spent Zonyl FSA ${ }^{\circledR}$}

The subject rare earth elements could be separated from the sedimented Zonyl FSA ${ }^{\circledR}$ phase by filtration, and the sedimented liquid phase similar to what existed before extraction was formed by adding a buffer solution $(\mathrm{pH}=4)$ in the filtrate containing the Zonyl FSA ${ }^{\circledR}$. Based on this phenomenon, the stripping experiments for rare earth elements were performed again using the spent Zonyl FSA ${ }^{\circledR}$. 
The related findings are shown below in Table 2. Part of the heavy elements has a higher extraction percentage in the second extraction compared to the first extraction. Because part of the Zonyl FSA was lost during the recycling procedure, the component balance was changed in each fluorinated carbon chain number (6-8) of Zonyl FSA ${ }^{\circledR}$. Thereby, the extraction selectivity for heavy elements was relatively increased. Zonyl FSA ${ }^{\circledR}$ was found to be reusable for the extraction and stripping of rare earth elements.

Table 2. Comparison of extraction percentages in first and second extraction times.

\begin{tabular}{ccccccccccccccccc}
\hline Metal & Sc & Y & La & Ce & Pr & Nd & Sm & Eu & Gd & Tb & Dy & Ho & Er & Tm & Yb & Lu \\
\hline 1st Extraction \% & 97 & 94 & 97 & 49 & 100 & 85 & 96 & 97 & 94 & 88 & 95 & 95 & 95 & 94 & 94 & 94 \\
2nd Extraction \% & 80 & 100 & 93 & 53 & 100 & 84 & 100 & 100 & 100 & 94 & 100 & 100 & 94 & 100 & 100 & 100 \\
\hline
\end{tabular}

\subsection{Overview of Separation and Recycling System of Rare Earth Elements Using Zonyl FSA ${ }^{\circledR}$}

Extracting rare earth elements by Zonyl $\mathrm{FSA}^{\circledR}$ is a plausible recovery technique using a simple filtration operation, and the spent Zonyl FSA ${ }^{\circledR}$ can be reused. Therefore, a separation and recycling system for rare earth elements using Zonyl FSA ${ }^{\circledR}$ was constructed, with the subject scheme shown below in Figure 4. In this system, the Zonyl FSA ${ }^{\circledR}$ and THF were added to metal solutions containing rare earth elements (depicted in the figure), with the solution resultantly forming a homogeneous state by gentle shaking. In addition, a weak acid buffer solution is introduced into the solution to extract the rare earth elements, and the Zonyl FSA ${ }^{\circledR}$ is subsequently aggregated by centrifugation for a period. The sedimented Zonyl FSA ${ }^{\circledR}$ phase is ultimately retained on the filter. Then, only Zonyl FSA ${ }^{\circledR}$ is filtrated and the rare earth elements are recovered on the filter as hydroxides. In contrast, Zonyl FSA ${ }^{\circledR}$ solution is obtained as a filtrate to around a neutral $\mathrm{pH}(\mathrm{pH} \geq 6.5)$. Accordingly, it is capable as a second recycling product to be used again for separation and recovery, as demonstrated below in the figure.

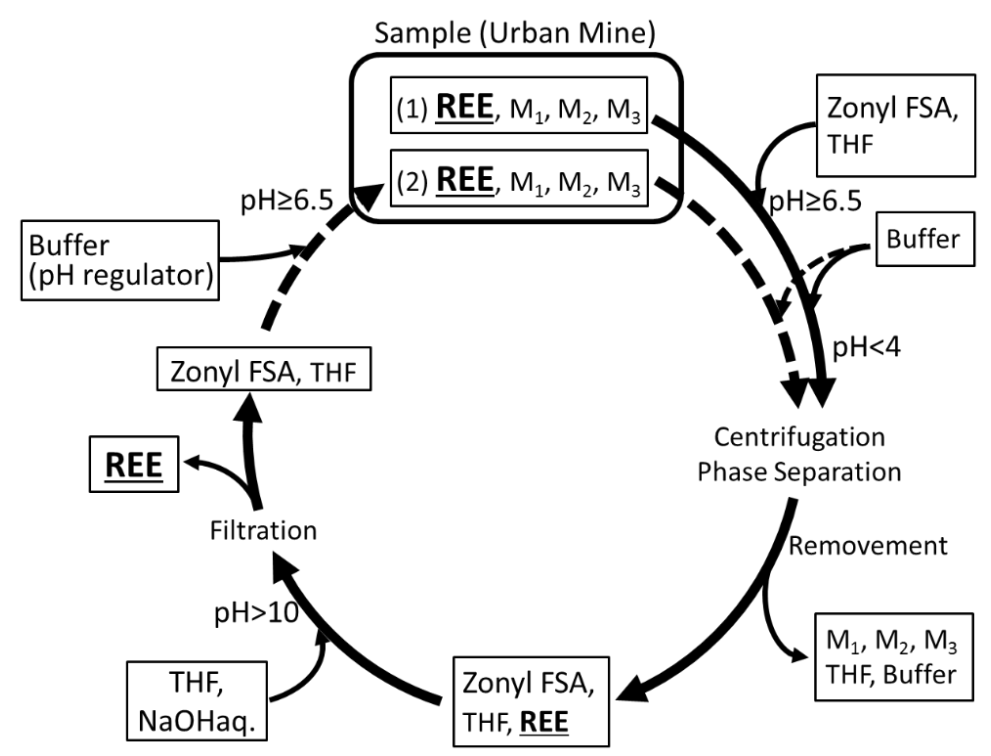

Figure 4. Separation and recycling system for rare earth elements using Zonyl FSA ${ }^{\circledR}$. REE: rare earth elements; $\mathrm{M}_{x}$ : coexistent metals. 


\section{Conclusions}

A homogeneous liquid-liquid extraction method (HoLLE) for metal elements using a Zonyl FSA ${ }^{\circledR}$ fluorosurfactant instead of a chelating agent was proposed. As a result, metal elements such as palladium, platinum, and rare earth elements were extracted at a very high percentage. This method is highly capable of extracting and stripping (with high efficiency) rare earth elements by HoLLE via the use of Zonyl FSA $^{\circledR}$. This method is expected to be a preprocessing technique for separating and recycling rare earth elements in electrical appliance components. Moreover, the developed process is capable of both the recycling of rare earth elements and the reuse of Zonyl FSA ${ }^{\circledR}$ as an extraction agent.

\section{Acknowledgments}

The authors thank Toshinori Fukazawa for assistance with the screening experiment of metals. This work was supported by JSPS KAKENHI Grant Numbers 15H02847. The authors would like to thank Enago (www.enago.jp) for the English language review.

\section{Author Contributions}

S.S. and S.I. conceived the experiments, and wrote the paper; S.S. designed experiments with contributions from S.I., O.O., T.K. and H.Y.; H.Y. was measured of metals by ICP-OES; S.S. performed experiments and interpretation.

\section{Conflicts of Interest}

The authors declare no conflict of interest.

\section{References}

1. Yang, J.; Kubota, F.; Baba, Y.; Kamiya, N.; Goto, M. One step effective separation of platinum and palladium in an acidic chloride solution by using undiluted ionic liquids. Solvent Extr. Res. Dev. Jpn. 2014, 21, 129-135.

2. Yang, J.; Kubota, F.; Baba, Y.; Kamiya, N.; Goto, M. Separation of precious metals by using undiluted ionic liquids. Solvent Extr. Res. Dev. Jpn. 2014, 21, 89-94.

3. Saitoh, T.; Sugiura, Y.; Asano, K.; Hiraide, M. Chitosan-conjugated thermos-responsive polymer for the rapid removal of phenol in water. React. Funct. Polym. 2009, 69, 792-796.

4. Kato, T.; Igarashi, S.; Ohno, O.; Watanabe, Y.; Murakami, K.; Takemori, T.; Yamaguchi, H.; Ando, R. Separation and recovery properties of rare earth elements using a $\mathrm{pH}$-sensitive polymer having benzoic acid substituent group. Bunseki Kagaku 2012, 61, 235-242.

5. Igarashi, S.; Saito, S.; Kato, T.; Okano, G.; Yamaguchi, H. Development of separation and recovery system of gold and rare earth elements using stimuli-responsive polymers-G-MOVE system and La-VEBA system. J. Surf. Finish. Soc. Jpn. 2012, 63, 630-632.

6. Saito, S.; Igarashi, S.; Yamaguchi, H. Selective collection characteristics and separation/recovery method of gold(III), silver(I) and platinum(II) with $\mathrm{pH}$-sensitive polymer under addition of L-ascorbic acid. Bunseki Kagaku 2014, 63, 791-795. 
7. Inoue, K.; Ohto, K.; Yoshizuka, K.; Shinbaru, R.; Baba, Y.; Kina, K. Adsorption behavior of metal ions on some carboxymethylated chitosans. Bunseki Kagaku 1993, 42, 725-731.

8. Parajuli, D.; Kawakita, H.; Inoue, K.; Ohto, K.; Kajiyam, K. Persimmon peel gel for the selective recovery of gold. Hydrometallurgy 2007, 87, 133-139.

9. Gurung, M.; Adhikari, B.B.; Kawakita, H.; Ohto, K.; Inoue, K. Recovery of Au(III) by using low cost adsorbent prepared from persimmon tannin extract. Chem. Eng. J. 2011, 174, 556-563.

10. Igarashi, S.; Yotsuyanagi, T. A novel homogeneous liquid-liquid Extraction by $\mathrm{pH}$ dependent phase separation with fluorocarbon ionic surfactant. In Proceedings of the Symposium on Solvent Extraction 1988, Tokyo, Japan, 5-7 December 1988; pp. 175-180.

11. Igarashi, S.; Yotsuyanagi, T. Temperature dependent phase transformation in the homogeneous liquid-liquid extraction with fluorocarbon surfactant. In Proceedings of the Symposium on Solvent Extraction 1989, Sendai, Japan, 9-11 November 1989; pp. 51-54.

12. Igarashi, S.; Yotsuyanagi, T. New homogeneous liquid-liquid extraction by phase separation and transformation with fluorocarbon surfactant and quaternary ammonium salt. In Solvent extraction 1990, Proceedings of the International Solvent Extraction Conference (ISEC '90), Kyoto, Japan, 16-21 July 1992; Sekine, T., Ed.; Elsevier: New York, NY, USA, 1992; pp. 1725-1730.

13. Wilkes, J.S.; Zaworotko, M.J. Air and water stable 1-ethyl-3-methylimidazolium based ionic liquids. J. Chem. Soc. Chem. Commun. 1992, 13, 965-967.

14. Yamaguchi, H. Did the study of ionic liquids begin from analytical chemistry? Bunseki 2007, 11, 608-609.

15. Igarashi, S.; Yotsuyanagi, T. Homogeneous liquid-liquid extraction by $\mathrm{pH}$ dependent phase separation with a fluorocarbon ionic surfactant and its application to the preconcentration of porphyrin compounds. Mikrochimica Acta 1992, 106, 37-44.

16. Oshite, S.; Igarashi, S. Homogeneous liquid-liquid extraction using perfluorooctanesulfonic acid and calcium and its application to the separation and recovery vitamin $\mathrm{B}_{12}$. J. Chem. Technol. Biotechnol. 1999, 74, 1183-1187.

17. Oshite, S.; Furukawa, M.; Igarashi, S. Homogeneous liquid-liquid extraction method for the selective spectrofluorimetric determination of trace amoutns of tryptophan. Analyst 2001, 126, 703-706.

18. Takahashi, A.; Ueki, Y.; Igarashi, S. Highly efficient homogeneous liquid-liquid extraction of rare earth metal ions from perfluorocarboxylate surfactant solutions using ion-pair phase separation systems. Solvent Extr. Res. Dev. Jpn. 2001, 8, 235-240.

19. Hoogerstraete, T.V.; Ohghena, B.; Binnemans, K. Homogeneous liquid-liquid extraction of rare earths with the betaine-batainium bis(trifluoromethylsulfonyl)imide ionic liquid system. Int. J. Mol. Sci. 2013, 14, 21353-21377.

20. Takagai, Y.; Igarashi, S. Homogeneous liquid-liquid extraction method as simple and powerful preconcentration for capillary gas chromatography and capillary electrophoresis. Am. Lab. 2002, 34, 29-30.

21. Fuchimukai, J.; Yamaguchi, H.; Meguro, Y.; Kubota, T.; Igarashi, S. Highly efficient homogeneous liquid-liquid extraction of lanthanoid ions in a strong acidic solution. Solvent Extr. Res. Dev. Jpn. 2006, 13, 139-146.

22. Sudo, T.; Igarashi, S. Homogeneous liquid-liquid extraction method for spectrofluorimetric determination of chlorophyll a. Talanta 1996, 43, 233-237. 
23. Ghiasvand, A.R.; Moradi, F.; Sharghi, H.; Hasaninejad, A.R. Determination of silver(I) by electrothermal-AAS in a microdroplet formed from a homogeneous liquid-liquid extraction system using tetraspirocyclohexylcalix[4]pyrroles. Anal. Sci. 2005, 21, 387-390.

24. Ghiasvand, A.R.; Shadabi, S.; Kakanejadifard, A.; Khajehkoolaki, A. Synthesis of a new $\alpha$-dioxime derivative and its application for selective homogeneous liquid-liquid extraction of $\mathrm{Cu}$ (II) into a microdroplet followed by direct GFAAS determination. Bull. Korean Chem. Soc. 2005, 26, 781-785.

25. Kato, T.; Igarashi, S.; Ishiwatari, Y.; Furukawa, M.; Yamaguchi, H. Separation and concentration of indium from a liquid crystal display via homogeneous liquid-liquid extraction. Hydrometallurgy 2013, 137, 148-155.

26. Yamaguchi, H.; Itoh, S.; Igarashi, S.; Kobayashi, T. Homogeneous liquid-liquid extraction of metal-1,10-phenanthoroline chelates in a weak acidic solution. Bunseki Kagaku 2005, 54, 227-230.

27. Sinha, S.P. Complexes of the Rare Earths; Pergamon Press Ltd.: Oxford, UK, 1966; p. 26.

28. Suzuki, Y. Kidorui no Hanashi [The Story of Rare Earth Elements]; Shokabo Publishing Co., Ltd.: Chiyoda, Japan, 1998; pp. 66-72.

29. Burgess, J. Metal Ions in Solution; Ellis Horwood Ltd.: New York, NY, USA, 1978; pp. 266-267.

(C) 2015 by the authors; licensee MDPI, Basel, Switzerland. This article is an open access article distributed under the terms and conditions of the Creative Commons Attribution license (http://creativecommons.org/licenses/by/4.0/). 